\title{
Deep Tendon Reflex
}

National Cancer Institute

\section{Source}

National Cancer Institute. Deep Tendon Reflex. NCI Thesaurus. Code C75446.

Contraction of a muscle triggered by a signal from a muscle spindle in response to a stimulus applied to a specific trigger point on the body. The streng th of the response can provide insight into central and peripheral nerve performance. 